\title{
Influence of flavonoids isolated from Satureja hortensis L. on hypercholesterolemic rabbits
}

Satureja hortensis L. (summer savory) is an annual herb with oval leaves and pink flowers widely distributed in Georgia, and locally named as 'Qondari'. Leaves and flowers of this plant are frequently used as tea or additive in commercial spice mixtures for many foods to offer aroma and flavor. S. hortensis L. has also been used as a folk remedy to treat various diseases and disorders such as cramps, muscle pain, indigestion, diarrhea, and infections, due to its antispasmodic, antidiarrheal as well as antimicrobial properties. Hypertension and hyperlipidemia are often the two coexisting risk factors in coronary artery disease. It has been well established that hypercholesterolemia is associated with various pathological processes such as cardiovascular diseases, diabetes mellitus, atherosclerosis, and thromboembolic disorders. ${ }^{[1]}$ The effect of flavonoids from $S$. hortensis L. on serum cholesterol of rabbits was investigated in the present study.

The experiments were carried out for 8 weeks in 20 male, albino, New Zealand rabbits weighing between 2.1 and $2.5 \mathrm{~kg}$. Rabbits were housed individually in stainless steel cages in an air-conditioned room $\left(23 \pm 1{ }^{\circ} \mathrm{C}\right)$ under a $12 \mathrm{~h}$ light/dark cycle and were acclimated for 2 weeks. One hundred and $50 \mathrm{~g}$ of regular rabbit chow was provided to each rabbit every day for a fixed duration of time. Water was given ad libitum. Animals were randomly divided into four groups of five rabbits each. (1) The standard diet group (Control), (2) high cholesterol diet group (Chol)-cholesterol, dissolved in sunflower-seed oil, administered daily p.o. $0.3 \mathrm{~g} / \mathrm{kg}$ B.W; (3) flavonoids group (F) flavonoids fraction, dissolved in distilled water, administered daily intramuscularly in a dose of $10 \mathrm{mg} / \mathrm{kg}$ of B.W. Flavonoids fraction was received from the air-dried plant material of $S$. hortensis L. by the method of Zaprometov. ${ }^{[2]}$ (4) high cholesterol diet plus flavonoids group $(\mathrm{Chol}+\mathrm{F}): 0.3 \mathrm{~g} / \mathrm{kg}$, cholesterol p.o. $+10 \mathrm{mg} / \mathrm{kg}$, flavonoids fraction i.m. Blood was collected from marginal ear vein from each animal and after clotting, centrifuged at $1000 \mathrm{X}$ g for $10 \mathrm{~min}$ at $4{ }^{\circ} \mathrm{C}$ to obtain serum. The serum cholesterol was estimated before starting (basal value) and at the end of 8 weeks of treatment by standard method using "Lachema” kits (Czech Republic).

The results are expressed as mean \pm SD. Inter-group comparisons among the 4 groups were determined by oneway ANOVA followed by Scheffe's ' $F$ ' test. All analyses were performed using the GraphPad Prism software version 4.01; $\mathrm{P}<0.05$ was considered statistically significant.

Mean serum cholesterol values at basal and at the end of 8 weeks of all groups of rabbits are shown in Figure 1. The difference in pre- and post-experiment serum cholesterol in control and F group was not statistically significant $(\mathrm{P}>0.05)$.
There was a significant increase in the mean serum cholesterol levels at the end of 8 weeks in the Chol group of rabbits from $1.12 \pm 0.14$ to $12.53 \pm 0.62 \mathrm{mmol} / \mathrm{L}(\mathrm{P}<0.0001)$. The corresponding rise, which was also significant in the Chol $+\mathrm{F}$ group of rabbits, was from $1.07 \pm 0.09$ to $5.34 \pm 0.28 \mathrm{mmol} /$ $\mathrm{L}(\mathrm{P}<0.001)$. However, when the mean post-experiment serum cholesterol levels of Chol and Chol $+\mathrm{F}$ groups of rabbits were compared, the Chol+F group showed a significantly lower value than the Chol group $(\mathrm{P}<0.001)$. Thus, fraction $\mathrm{F}$ had significantly prevented the diet-induced rise of serum cholesterol.

Figure 1. Plasma total cholesterol concentration in rabbits before and after 8 weeks of experimental period.

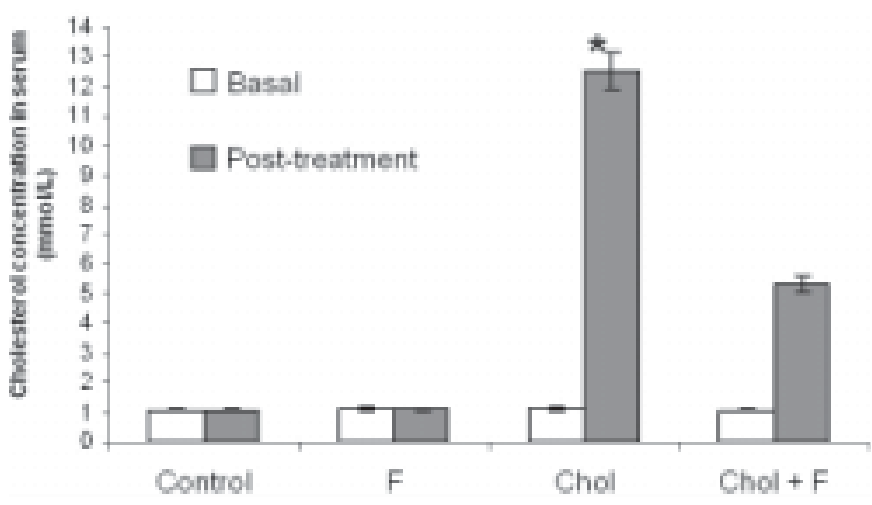

Chol-cholesterol; F-flavonoid fraction treated. ${ }^{*} \mathrm{P}<0.001$ in comparison to those of Chol+F group. Values are mean $\pm S D$. $n=5$ in each group.

Administration of flavonoids isolated from S. hortensis L. along with cholesterol in rabbits has resulted in a significant attenuation of rise in serum cholesterol value after 8 weeks, when compared to the cholesterol alone group. This suggests the cholesterol-lowering effect of fraction $\mathrm{F}$ in a situation of rising serum cholesterol. Though the hypolipidemic properties of flavonoids are well known, ${ }^{[3]}$ such an effect of flavonoids from $S$. hortensis L. has not yet been shown.

Further studies are necessary to elicit the mechanism of action as well as to confirm these findings.

\section{Acknowledgments}

This work was supported by INTAS grant 99-1768. 
D. Mchedlishvili, Z. Kuchukashvili, T. Tabatadze, G. Davitaia

Iv. Javakhishvili State University, Biological Faculty, Department of Biophysics, Tbilisi, Georgia Email: gia_davitaia@yahoo.com

\section{References}

1. Pyorala K, Laakso M, Uusiputa M. Diabetes and atherosclerosis: An epidemiological view. Diabetes 1987;3:463-524.

2. Zaprometov MN. The basis of biochemistry of phenolic compounds. Moscow: Visshaja Shkola (in Russian); 1974.

3. Chan PT, Fong WP, Cheung YL, Huang Y, Ho WK, Chen ZY. Jasmine green tea epicatechins are hypolipidemic in hamsters fed a high fat diet. J Nutr 1999;129:1094-101.

\section{WHO Medicines Bookshelf Version 4.0}

WHO Medicines Bookshelf CDs distributed with this issue were provided free of cost by the WHO, Avenue Appia 20, CH-1211 Geneva 27, Switzerland.

(E-mail: edmdoccentre@who.int; Web site: http://www.who.int/medicines).

We thank the WHO for their generous gesture.

-Chief Editor, IJP

\section{..... Now awailable ..... \\ ETHNOVET HERITAGE \\ Indian Ethnoveterinary Medicine \\ An overview}

Editors: Jayvir Anjaria, Minoo Parabia and Shailendra Dwivedi

Publishers: Pathik Enterprise, Ahmedabad. India

Price: Rs. 2250/- (US\$ 70) . Special 50\% discount to, Researchers, Ethnovets, Students \& Educational India: Rs. 1125/- (US\$ 35). Packing-forwarding-Reg. Postage/Courier extra (India: Rs. 150-200/-; Foreign: US\$ 20)

E-mail: anjariaad1@sancharnet.in 